nachgewiesen wurde. Aus der Stellungnahme des sachverständigen Zeugen D... ergibt sich, dass die Zeichnungen weder einen materiellen noch einen künstlerischen Wert aufweisen. Das damit im Wesentlichen verbleibende immaterielle Interesse des Klägers am Besitz und an der Sammlung der Zeichnungen wurde vom Beklagten zu Recht als nachrangig gegenüber dem Interesse am Schutz des Rechtsverkehrs vor Betrugsstraftaten eingestuft.

[29] II. Da die Sicherstellung rechtmäßig ist, hat der Kläger keinen Herausgabeanspruch im Wege der Vollzugsfolgenbeseitigung gem. § 113 Abs. 1 S. 2 VwGO.
[30] Der Kläger kann die Herausgabe schließlich auch nicht gem. § 41 Abs. 1 S. 1 ASOG verlangen, weil die Voraussetzungen für die Sicherstellung nicht weggefallen sind. Eine gegenwärtige Gefahr der Begehung von Betrugsstraftaten mithilfe der Fälschungen besteht weiterhin und würde sich im Fall einer Herausgabe der Bilder an den Kläger erneut aktualisieren ( $\$ 41$ Abs. 1 S. 3 ASOG).

[31] Ob die Zeichnungen an den Kläger, der seine Eigentümerstellung nicht belegt hat, zurückzugeben wären oder an Herrn M..., bei dem die Bilder sichergestellt wurden (vgl. § 41 Abs. 1 S. 2 ASOG), kann damit offen bleiben.

\title{
Temporäre Kunst vor der Frauenkirche Dresden
}

Verwaltungsgericht Dresden, Beschluss vom 15.02.2017, 12 L 190/17

Eine von der Stadt erteilte Sondernutzungserlaubnis zur Aufstellung eines Kunstwerkes kann einen Einzelnen nicht in seinen Rechten verletzten. Ein Bürger ist nicht davor gesetzlich geschützt, dass der Anblick von Kunst bei ihm „anstößige Wertung erregt“ (Leitsatz der Redaktion)

\section{Gründe}

- Der Antragsteller begehrt im einstweiligen Anordnungsverfahren die Verpflichtung der Antragsgegnerin, das auf dem NMarkt in D vor der F-Kirche aufgestellte Kunstwerk "Monument" zu entfernen.

Bei dem temporären Kunstwerk "Monument" des Künstlers $\mathrm{H}$ handelt es sich um die Installation von drei Bussen, die auf einem Sockel auf dem N-Markt hochkant aufgestellt sind. Diese sollen an drei Linienbusse erinnern, die in Aleppo zum Schutz vor Scharfschützen aufgestellt worden waren. Die Installation ist Teil des Kulturfestivals "Am Fluss. Zu Kulturen des Ankommens" im Rahmen der Initiative W. Die von den Museen der Stadt D/Kunsthaus D beantragte Sondernutzungserlaubnis für die Nutzung einer Teilfläche des N-Marktes für die Aufstellung des Kunstwerkes hat die Antragsgegnerin am 2. Februar 2017 erteilt.

Der Antragsteller hat am 8. Februar 2017 den vorliegenden Antrag auf Gewährung einstweiligen Rechtsschutzes gestellt. Er ist der Auffassung, dass es - insbesondere auch im Gedenken an die Opfer des 13. Februar 1945 - unangemessen und respektlos sei, diese „Kunstart" vor der D F-Kirche aufzustellen. In der allgemeinen Stimmungslage sei sie eine Provokation. Das Gedenken an die Opfer des 2. Weltkriegs werde mit der aktuellen Situation in Aleppo vermischt. Die "Kunst" werde Tag und Nacht von Polizisten bewacht. Dafür würden Steuergelder aufgewendet.

Die Antragsgegnerin ist dem Antrag entgegen getreten und verweist darauf, dass nicht erkennbar sei, inwiefern der Antragsteller in eigenen Rechten verletzt sei. Ob eine Sondernutzung erteilt werden könne, bemesse sich ausschließlich nach straBenrechtlichen Kriterien, d.h. nach solchen Belangen, welche einen Bezug zur öffentlichen Straße hätten. Dies seien Belange zum Schutz der öffentlichen Straßenlage unter Aufrechterhaltung der Sicherheit und Leichtigkeit des Verkehrs sowie Belange der öffentlichen Sicherheit und Ordnung. Straßenfremde Kriterien könnten nicht zur Beurteilung über die Zulässigkeit des Sondernutzungsantrages herangezogen werden. Insbesondere obliege es nicht dem Straßenbaulastträger, über den Inhalt einer Kunstausübung zu befinden.

Der Antrag hat keinen Erfolg. Er ist bereits unzulässig.

Nach § 123 Abs. 1 VwGO kann das Gericht, auch schon vor Klageerhebung, eine einstweilige Anordnung in Bezug auf den Streitgegenstand treffen, wenn die Gefahr besteht, dass durch eine Veränderung des bestehenden Zustands die Verwirklichung eines Rechts des Antragstellers vereitelt oder erschwert werden könnte. Einstweilige Anordnungen sind auch zur Regelung eines vorläufigen Zustands in Bezug auf ein streitiges Rechtsverhältnis zulässig, wenn diese Regelung, um wesentliche Nachteile abzuwenden oder drohende Gewalt zu verhindern oder aus anderen Gründen nötig erscheint. Der geltend gemachte Anspruch (Anordnungsanspruch) und die Notwendigkeit der vorläufigen Regelung (Anordnungsgrund) sind glaubhaft zu machen ( $§ 123$ Abs. 3 VwGO iVm § 920 Abs. 2 ZPO).

Der Antrag ist unzulässig. Dem Antragsteller fehlt es an der erforderlichen Antragsbefugnis (§ 42 Abs. 2 VwGO analog). 
Für das Vorliegen der Antragsbefugnis ist es erforderlich, dass der Antragsteller geltend macht, durch den angegriffenen Verwaltungsakt in seinen Rechten verletzt zu sein. Ausreichend ist hierbei die bloße Möglichkeit einer Rechtsverletzung (Kopp/ Schenke, VwGO 22. Aufl., § 123 Rn. 20, § 42 Rn. 59). Dies setzt aber voraus, dass die Anwendung von Rechtssätzen möglich erscheint, die (abstrakt) auch dem Schutz der Interessen von Personen zu dienen bestimmt sind, die sich in der Lage des Antragstellers befinden. Der in Frage stehende Rechtssatz muss ausschließlich oder - neben anderen Zwecken - zumindest auch dem Schutz der Interessen des Antragstellers dienen (Kopp/Schenke, aaO Rn. 66, 78). Solche Rechtssätze sind hier nicht erkennbar. Soweit der Antragsteller meint, die Aufstellung der Busse vor der F-Kirche sei respektlos und unangemessen, dies sei in der allgemeinen Stimmungslage als eine Provokation anzusehen und es erfolge eine (unzulässige) Vermischung des Gedenkens an die Opfer des 2. Weltkrieges mit der aktuellen Situation in Aleppo, ist ein Rechtssatz, der zumindest auch dazu bestimmt ist, die Interessen eines (auch zufälligen) Betrachters eines Kunstwerks dahingehend zu schützen, dass dieses bei ihm keinerlei anstößige Wertung erregt, nicht erkennbar.

Soweit der Antragsteller rügt, dass die Kunstinstallation auf Steuerkosten von der Polizei bewacht werde, ist kein Rechtssatz ersichtlich, der die Interessen eines Bürgers an einer bestimmten Verwendung der staatlichen Steuereinnahmen schützt.

Im Übrigen wäre der Antrag auch unbegründet. Die Entscheidung der Antragsgegnerin über die Erteilung der beantragten Sondernutzungserlaubnis beruht auf § 18 SächsStrG iVm der Sondernutzungssatzung der Antragsgegnerin. Zu prüfen sind dabei Belange, die einen Bezug zur öffentlichen Straße haben. Eine Bewertung des Kunstwerks, das der grundgesetzlich geschützten Kunstfreiheit (Art. 5 Abs. 3 GG) unterliegt und im öffentlichen Straßenraum aufgestellt werden soll, ist dagegen nicht vorzunehmen.

Die Kosten des Verfahrens sind nach § 154 Abs. 1 VwGO dem Antragsteller als der unterlegenen Prozesspartei aufzuerlegen.

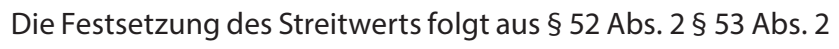
Nr. 1, § 63 Abs. 2 GKG in Übereinstimmung mit Ziffer 1.5 des Streitwertkatalogs für die Verwaltungsgerichtsbarkeit 2013 (NVwZ, Beilage 2/2013, S. 57 ff.). Für eine Halbierung des Streitwerts besteht keine Veranlassung, da eine stattgebende Entscheidung die Hauptsache vorweg nehmen würde. 